Critical Mass and Network Size with Application to the US FAX Market

by

Nicholas Economides and Charles Himmelberg

EC-95-11

August 1995 


\title{
Critical Mass and Network Size with Application to the US FAX Market*
}

\author{
Nicholas Economides** and Charles Himmelberg ${ }^{* * *}$
}

August 1995

\begin{abstract}
We analyze the equilibrium size of networks under alternative market structures. Networks are characterized by positive size externalities (commonly called "network externalities"). That is, the benefits of the addition of an extra node (or an extra customer) exceed the private benefits accruing to the particular node (or customer). A direct consequence of this demand structure is that perfect competition does not implement the optimal outcome. Because of the externality, there exists a range of prices within which three different network sizes can be supported as equilibria: a zero size network, an intermediate size that is unstable, and a large stable and Pareto optimal one. We expect that the market will select the largest of the three equilibrium networks. As a result, small networks will not observed. We call critical mass the size of the smallest network that can be supported in equilibrium. Alternative allocation systems internalize the network externality to different degrees, and therefore result in a variety of sizes of critical masses and price-network size paths. A welfare-maximizing planner supports a larger network than results in perfect competition. Surprisingly, a monopolist, even if allowed to influence consumers' expectations, always chooses a network of smaller size than in perfect competition. Oligopolists of compatible network goods support networks of smaller size than perfect competition and larger than monopoly. We extend our results to durable goods in a dynamic setting. In the presence of a downward time trend for industry marginal cost, the presence of network externalities increases the speed at which market demand grows. We use this prediction to calibrate the model and obtain estimates of the parameter measuring a consumer's valuation of the installed base (i.e., the network effect) using aggregate time series data on prices and quantities in the US fax market.
\end{abstract}

Key words: networks, critical mass, fax, externalities

JEL Classification: L1, D4

*We thank Paul David, Birgit Grodal, Peter Howitt, Boyan Jovanovic, Paul Krugman, Ed Lazear, Pino Lopomo, Carmen Matutes, Joe Ostroy, Sam Peltzman, Jean-Charles Rochet, Hal Varian, Larry White, and participants of the 22nd annual Telecommunications Policy Research Conference, the conference "Networks and Competition" at Toulouse, and at seminars at the Federal Reserve Bank of Philadelphia, New York University, Rutgers, Stanford, UC Berkeley, UCLA, the University of Chicago, and the University of Michigan for comments and suggestions. ** Stern School of Business, New York University, New York, NY 10012-1126, (212) 998-0864, -0870, FAX (212) 995-4812, neconomi@stern.nyu.edu, http://edgar.stern.nyu.edu/networks

**** Columbia Business School, New York, NY 10027, chimmelb@groucho.gsb.columbia.edu. 


\section{Critical Mass and Network Size with Application to the US FAX Market}

\section{Introduction}

Network industries are common. Among them one can name telephony, electricity, roadways, railroads, and facsimiles. A central feature of networks is that an increase of sales of network services through the expansion of the network creates external (not market-mediated) benefits for other buyers (network participants) because the creation of new goods affects directly and positively the utility function of every participant. The resulting consumption economies of scope are called direct network externalities. ${ }^{1,2}$

Industries with network externalities typically exhibit a positive critical mass -- i.e., small networks are not observed at any price. This is a central feature of network industries and is likely to be present in a variety of market structures or allocation mechanisms. However, the presence of network externalities and critical mass have significant repercussions for the analysis of conduct, market structure, and performance, and these will be the focus of this paper.

We construct a general model of network externalities and establish conditions for the existence of critical mass under perfect competition, monopoly, oligopoly, and welfare maximization. When we compare the resulting prices and network sizes for these market structures, we find that perfect competition is inefficient, provides a smaller than optimal network, and does not decentralize the welfare-maximizing solution. We further find that a monopolist who is able to influence expectations will generally choose to create a smaller network than would result under perfect competition. The same is true for oligopolists producing compatible goods.

1 Non-network industries that produce complementary (vertically-related) components typically exhibit indirect network externalities as the addition of new varieties of one type of components affect positively but indirectly the utility of all participants through the reduction of prices.

2 Economides and White (1994) distinguish between two-way networks, one-way networks, and industries of compatible vertically-related components. 
We next extend our results to a dynamic setting and to durable goods. With perfectly elastic supply, the durable goods problem can be reduced to a single-period problem. With inelastic supply, we characterize the equilibrium network paths. In the final section, we present an analysis of the market for facsimile machines as an example of an emerging network, ${ }^{3}$ and we show how time series data on prices and quantities can be used to estimate the value of the network externality.

The structure of the paper is as follows. Section 2 presents the basic model. Section 3 analyzes the existence of critical mass and its size for different ownership structures. Specifically, section 3.1 analyzes perfect competition, section 3.2 discusses welfare maximization, section 3.3 discusses monopoly and section 3.4 discusses oligopoly. Section 4 discusses dynamics for non-durable and durable goods under perfect competition and the applies the analysis to the U.S. FAX market. Section 5 presents concluding remarks.

\section{The Model}

We first analyze a static one-period world. Our model captures the existence of network externalities through expectations that are fulfilled at equilibrium. We assume that consumers expect a network of size $n^{e}$ which we normalize to be between 0 and $1,0 \leq n^{e} \leq 1$. We define a network externalities function that captures the influence of network size expectations on the willingness to pay for the good provided through the network. ${ }^{4}$ Let the network externalities

3 Our analysis is complementary to the extensive literature on network externalities and the traditional applied analysis of specific networks such as telecommunications and electricity.

4 See Economides and White (1994) among others for a justification of the emergence of network externalities. In industries of complementary goods (network industries or otherwise) the addition of new components may directly affect positively the utility of consumers or may indirectly enhance the value of goods already provided in the network. As a rule, direct effects occur in two-way networks, such as telephone and road networks, where reciprocity is present (a phone call from A to B is distinct from a phone call from B to A, and they are both feasible and demanded) and consumers are identified with network nodes. Indirect network externalities typically occur in one-way networks (such as an Automatic Teller Machine network) where two 
function be $h\left(n^{e}\right)=k+\delta f\left(n^{e}\right)$. Here, $k$ gives the value of the good in the absence of network effects, $\delta$ is an indicator function taking the value 1 if there are network externalities, and $\mathrm{f}\left(\mathrm{n}^{\mathrm{e}}\right)$ measures the network effect. We normalize by setting $f(0)=0$, so that a network of size 0 has no effect on willingness to pay. Since the externalities are positive, we assume $f^{\prime}()>$.0 , so that larger expected sizes of networks give higher individual utility. We also assume $\mathrm{f}^{\prime \prime}() \leq$.0 , so that the marginal network externality is not increasing in network size.

We assume that for a consumer indexed by $y$, the willingness to pay for one unit of the good in a network of expected size $n^{e}$ is $u\left(y, n^{e}\right)=y h\left(n^{e}\right) .{ }^{5}$ Let the cumulative distribution function of types be $\mathrm{G}(\mathrm{y})$. We assume that $\mathrm{G}(\mathrm{y})$ is continuous with positive density $\mathrm{G}^{\prime}(\mathrm{y})$ everywhere on its support, which is normalized to be $[0,1] .^{6,7}$ Given expectations $\mathrm{n}^{\mathrm{e}}$ and price $p$, the index $y^{*}=m\left(p, n^{e}\right)$ of the marginal consumer is the value $y$ that solves $u\left(y, n^{e}\right)$ $=\mathrm{p}$. If price is so low that all consumers wish to purchase, then there is no interior solution, and $\mathrm{y}=0$. Similarly, at very high prices, $\mathrm{y}=1$. More formally,

$$
\mathrm{y}^{*} \equiv \mathrm{m}\left(\mathrm{p}, \mathrm{n}^{\mathrm{e}}\right)=\left[\begin{array}{ll}
0 & \text { if } \mathrm{p} / \mathrm{h}\left(\mathrm{n}^{\mathrm{e}}\right)<0 \\
\mathrm{p} / \mathrm{h}\left(\mathrm{n}^{\mathrm{e}}\right) & \text { otherwise } \\
1 & \text { if } \mathrm{p} / \mathrm{h}\left(\mathrm{n}^{\mathrm{e}}\right)>1 .
\end{array}\right.
$$

different types of components (ATM machines and Bank accounts) are combined to create a demanded good, and reciprocity is not present. The analysis of one-way networks also applies to markets with compatible components and markets of vertically-related goods in general.

5 The multiplicative specification allows different types of consumers to receive differing values of "network externality" from the same network. Our assumption diverges from most of the literature (Katz and Shapiro (1985), Cabral (1990), Economides (1995)), which uses an additive utility specification, so that all consumers receive the same benefit from the same network.

6 It follows that the inverse $G^{-1}(n)$ exists for $n \in[0,1]$.

7 We intentionally allow the existence of some types of consumers (of low y) who have little or no use for the good provided through the network. 
Given expectations and price, all consumers with indices higher than $y \geq y^{*}$ buy the good, so that the size of the network at price $\mathrm{p}$ is,

$$
\mathrm{n}=1-\mathrm{G}\left(\mathrm{y}^{*}\right)=1-\mathrm{G}\left(\mathrm{m}\left(\mathrm{p}, \mathrm{n}^{\mathrm{e}}\right)\right)
$$

This defines the demand for the network good at price p. Since G(.) is strictly monotonic, its inverse exists, and, when $0 \leq \mathrm{p} / \mathrm{h}(\mathrm{n}) \leq 1$, we can write the willingness to pay for the last consumer in a network of size $n$ with expectations $n^{e}$ as

$$
\mathrm{p}\left(\mathrm{n}, \mathrm{n}^{\mathrm{e}}\right)=\mathrm{h}\left(\mathrm{n}^{\mathrm{e}}\right) \mathrm{G}^{-1}(1-\mathrm{n})
$$

Seen as a function of its first argument, this is just an inverse demand function, and therefore,

$$
\mathrm{p}_{1}=-\mathrm{h} / \mathrm{G}^{\prime}<0 .^{8}
$$

Because of network externalities, expectations affect positively the willingness to pay,

$$
\mathrm{p}_{2}=\mathrm{h}^{\prime} \mathrm{G}^{-1}(1-\mathrm{n})>0
$$

\section{Critical Mass}

For normal goods that do not exhibit network externalities, demand slopes downward; as price decreases, more of the good is demanded. This fundamental relationship may fail in goods with network externalities. For network goods, the willingness to pay for the last unit increases as the number expected to be sold increases. If expected sales rises with actual sales, then in equilibrium the willingness to pay for the last unit may increase with the number of units sold. Thus, for goods with network externalities, the (fulfilled expectations) demand-price schedule may not slope downward everywhere. In such markets, as costs decrease (in the comparative statics sense) we may observe discontinuous expansions in sales rather than the

\footnotetext{
8 Subscript $\mathrm{i}$ in $\mathrm{p}_{\mathrm{i}}$ indicates the derivative with respect to the ith argument of the function.
} 
smooth expansion along a downward slopping demand curve. In particular, we may observe a discontinuous start of the network: as costs decrease, the network starts with a significant market coverage (say $10 \%$ of the market) rather than starting with $0.1 \%$ coverage.

Critical mass, denoted by $\mathrm{n}^{0}$, is defined as the smallest network size that can be sustained in equilibrium. We will argue that, for many network goods, the critical mass is of significant size, and therefore for these goods small market coverage will never be observed -- either the market does not exist or it has significant coverage.

The concept of critical mass formalizes the "chicken and the egg" paradox: many consumers are not interested in purchasing the good because the installed base is too small, and the installed base is too small because an insufficiently small number of consumers have purchased the good. Thus, consumers' expectations of no network good provision may be fulfilled. However, for a range of costs, expectations of positive level(s) of sales of the network good are also fulfilled. Often, there are multiple fulfilled expectations equilibria. Consumers and producers can coordinate to reach any one of them. We will assume that they will reach the equilibrium of the largest network size. Thus, when more than one network size is supported by the same price, we select as the equilibrium the highest network size supported by that price; this network size Pareto dominates the other network sizes supported by the same price.

In equilibrium, expectations are fulfilled so that $n=n^{e} .9$ Thus, the mapping

$$
p(n, n)=h(n) G^{-1}(1-n) .
$$

defines the price level that supports an equilibrium network of size n. Alternatively, equation (4) can be thought of as defining the size(s) of the network that can be supported by a fulfilled expectations equilibrium for a given price, i.e., as defining the fulfilled expectations demand.

Figure 1 shows the construction of a typical fulfilled expectations demand. The curves

9 See Katz and Shapiro (1985). 


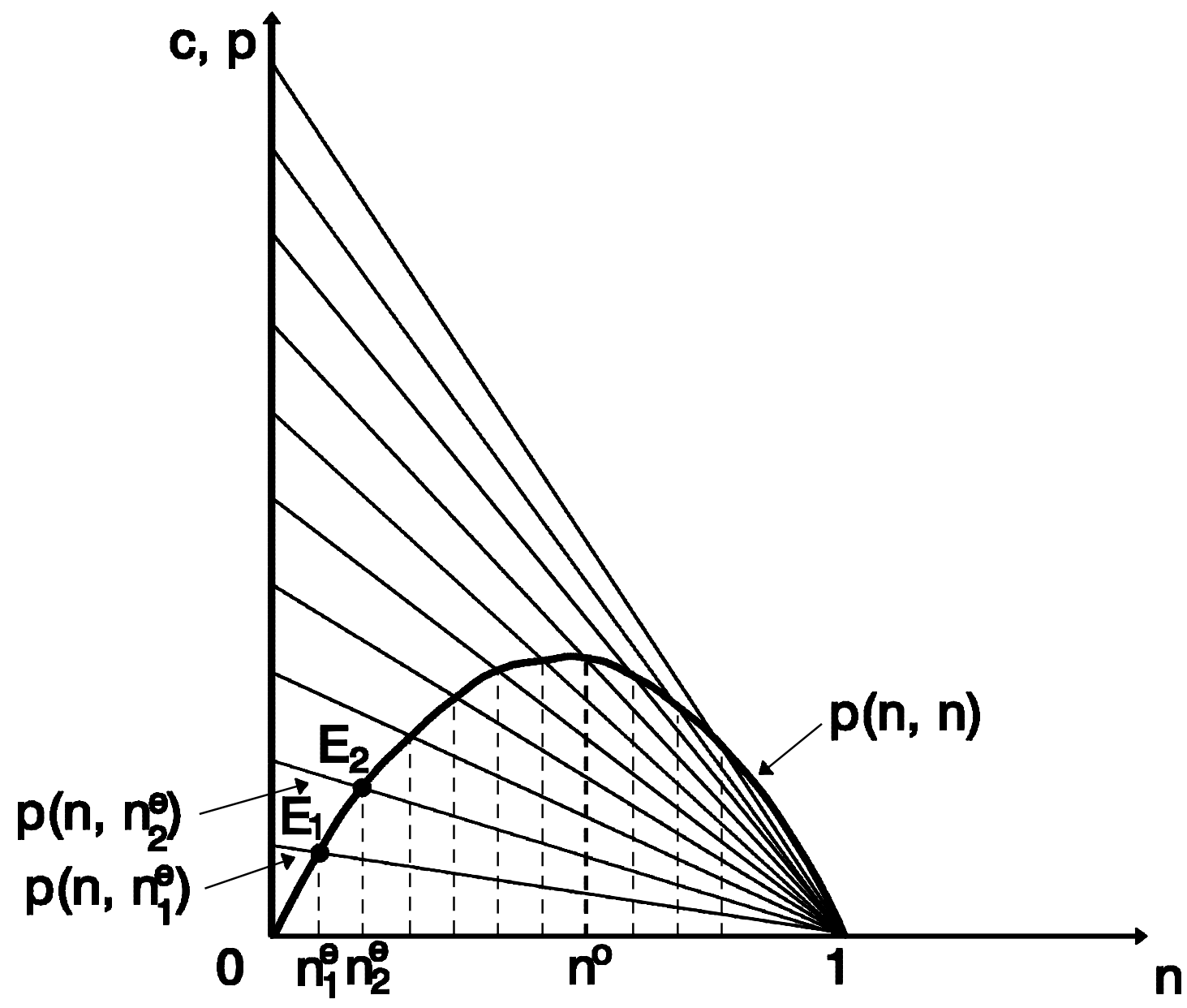

Figure 1: Construction of a fulfilled expectations demand $p(n, n)$.

$\mathrm{p}\left(\mathrm{n}, \mathrm{n}_{1}{ }^{\mathrm{e}}\right)$ and $\mathrm{p}\left(\mathrm{n}, \mathrm{n}_{2}{ }^{\mathrm{e}}\right)$ show the willingness to pay, given different sizes of the installed base that consumers expect to emerge in equilibrium, where $n_{2}^{\mathrm{e}}>\mathrm{n}_{1}^{\mathrm{e}}$. The point labeled $E_{1}$ on the first curve represents the point at which $\mathrm{n}$ equals $\mathrm{n}_{1}^{\mathrm{e}}$, and analogously, $\mathrm{E}_{2}$ on the second curve represents the point at which $n$ equals $n_{2}^{\mathrm{e}}$. The locus of all such points traces out the fulfilled expectations demand curve. Observe that the fulfilled expectations demand $p(n, n)$ is not monotonic. Also note that, in addition to the prices indicated by the inverted-U shaped curve in Figure 1, the fulfilled expectations demand curve $p(n, n)$ also includes the entire vertical axis at zero, as indicated by the thicker line. This is because at any marginal cost $\mathrm{c}>\mathrm{k}$ a network 
of zero size is a fulfilled expectations equilibrium (Figure 1 is drawn for the special case when $\mathrm{k}=0$; the general cases are shown in Figure 2). Thus, in general, the fulfilled expectations demand consists of the vertical axis above $\mathrm{k}$ and the inverted-U curve that starts at $\mathrm{k}$.

\subsection{Perfect Competition}

Let the market for the network good or service be perfectly competitive and let the constant marginal cost be c. In a perfectly competitive environment, firms set price equal to marginal cost and offer an infinitely elastic supply. Therefore, in equilibrium,

$$
\mathrm{p}(\mathrm{n}, \mathrm{n})=\mathrm{c} .
$$

To determine the critical mass of a network, we analyze the shape of the fulfilled expectations demand $p(n, n)$, defined by equation (4). We begin by establishing the value of $p(n, n)$ at the corners. First note that the marginal consumer is willing to pay $\mathrm{k} \geq 0$ at a fulfilled expectations equilibrium network of size zero, and is willing to pay zero when the network size is one. Formally,

$$
\lim _{n \rightarrow 0} p(n, n)=k G^{-1}(1)=k \geq 0, \quad \lim _{n \rightarrow 1} p(n, n)=0,
$$

since $\lim _{n \rightarrow 0} h(n)=k, G^{-1}(1)=1$ and $G^{-1}(0)=0$. The second limit says that to achieve a very large size, a network has to include even consumers of very low willingness to pay.

The slope of the fulfilled expectations demand $\mathrm{p}(\mathrm{n}, \mathrm{n})$ is ${ }^{10}$

$$
d p(n, n) / d n=p_{1}+p_{2}=-h(n) / G^{\prime}+h^{\prime}(n) G^{-1}(1-n) .
$$

The first term measures the slope of the inverse demand disregarding the effects of expectations. The second term captures the effect of a marginal increase in the expected size of the network

10 This can also be found by implicitly differentiating equation (2) with respect to $\mathrm{n}$ after substituting $\mathrm{n}^{\mathrm{e}}=\mathrm{n}$. Then, $1=-\mathrm{G}^{\prime}\left(\mathrm{p}^{\prime} / \mathrm{h}-\mathrm{ph}^{\prime} / \mathrm{h}^{2}\right) \Leftrightarrow \mathrm{p}^{\prime}=\mathrm{ph} / \mathrm{h}-\mathrm{h} / \mathrm{G}^{\prime}=\mathrm{G}^{-1}(1-\mathrm{n}) \mathrm{h}^{\prime}-\mathrm{h} / \mathrm{G}^{\prime}$, where $\mathrm{p}^{\prime}=\mathrm{dp} / \mathrm{dn}$ and $\mathrm{h}^{\prime}=\mathrm{dh} / \mathrm{dn}$, and we used the rule $\mathrm{dG}^{-1}(\mathrm{x}) / \mathrm{dx}=1 / \mathrm{G}^{\prime}\left(\mathrm{G}^{-1}(\mathrm{x})\right)$. 
on the marginal consumer, i.e., the increase in the willingness to pay of the last subscriber to the network created by his action in joining the network. If the network gets very large, the last consumer joining the network has a very low willingness to pay for it. Therefore, for very large networks, the effect of marginal expectations on the marginal consumer is negligible, i.e.,

$$
\lim _{n \rightarrow 1} p_{2}=\lim _{n \rightarrow 1} h^{\prime}(n) G^{-1}(1-n)=0
$$

It follows that for large $n$, the slope of $p(n, n)$ is negative,

$$
\lim _{n \rightarrow 1} \operatorname{dp}(n, n) / d n=\lim _{n \rightarrow 1} p_{1}+\lim _{n \rightarrow 1} p_{2}=\lim _{n \rightarrow 1} p_{1}=-h(1) G^{\prime}(1)<0
$$

The sign of $\lim _{n \rightarrow 0} d p(n, n) / d n$ depends on the values of the parameters of the market and is of crucial importance.

We assume that $\mathrm{p}(\mathrm{n}, \mathrm{n})$ is quasi-concave, i.e., single-peaked. Since we have showed that, for large $n, p(n, n)$ is decreasing, there are only two possibilities: either it is increasing for small $\mathrm{n}$, and decreasing for large $\mathrm{n}$ (inverted $\mathrm{U}$ or bell-shaped); or it is decreasing for all $\mathrm{n}$. The network has a positive critical mass if and only if $\mathrm{p}(\mathrm{n}, \mathrm{n})$ is increasing in $\mathrm{n}$ in the neighborhood of $n=0$, i.e., if $\lim _{n \rightarrow 0} d p / d n>0$. In this case, the function $p(n, n)$ is depicted on the left panel of Figure 2. Furthermore, $p(n, n)$ is increasing for small $n$, reaches a maximum at $\mathrm{n}^{0}$, and eventually decreases for large $\mathrm{n}$. The critical mass is the size of the network $n^{0}$ that corresponds to the maximum of $p(n, n)$. Let $c^{0} \equiv p^{0} \equiv p\left(n^{0}, n^{0}\right)$. At a network of critical mass size, the two opposite effects of a marginal increase in $n$ on willingness to pay are exactly counterbalanced.

For high levels of marginal cost (and therefore price) $c>c^{0}$, no consumer is willing to buy the good, and therefore the network does not exist. For $\mathrm{c}=\mathrm{c}^{0}$, the network appears with a positive size $n^{0}$. For $c<c^{0}$, there are two network sizes that are consistent with equation (4). This is not surprising because of the self-supporting nature of the network expansion. Following our convention, we will take the equilibrium size of the network to be the largest of the solutions. 

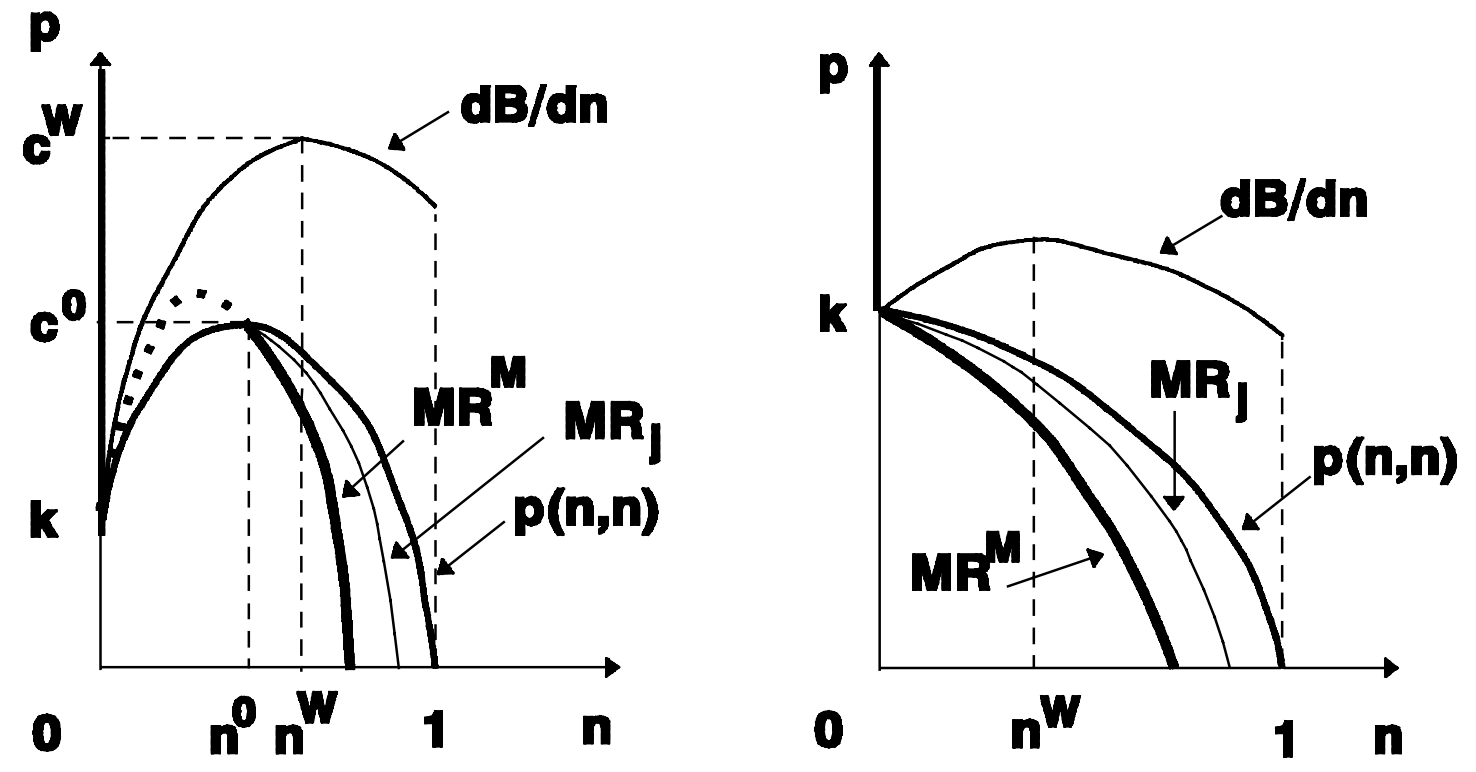

Figure 2: The fulfilled expectations demand with strong and weak network externalities.

Thus, as marginal cost decreases below $\mathrm{p}^{0}$, the equilibrium network size follows the outer branch of $\mathrm{p}(\mathrm{n}, \mathrm{n})$.

Lemma 1: Under perfect competition, a network exhibits a positive critical mass if and only if $\lim _{n \rightarrow 0} d p(n, n) / d n>0$.

The market does not have a positive critical mass when $\lim _{n \rightarrow 0} d p(n, n) / d n<0$. Such a case is depicted in Figure 2(b), where the function $\mathrm{p}(\mathrm{n}, \mathrm{n})$ is decreasing for all $\mathrm{n}$. The following theorem describes conditions on the extent of the network externality and the distribution of types under which networks have critical mass.

Theorem 1: A network has a positive critical mass if either (i) $k=0$, i.e., the utility of every consumer in a network of zero size is zero, or (ii) $\lim _{n \rightarrow 0} h^{\prime}(n)$ is sufficiently 
large, i.e., there are immediate and large external benefits to network expansion for very small networks, or (iii) $G^{\prime}(1)$ is sufficiently large, i.e, there is a significant density of high-willingness-to-pay consumers who are just indifferent on joining a network of approximately zero size.

In general,

$$
\lim _{n \rightarrow 0} d p(n, n) / d n=\lim _{n \rightarrow 0} h^{\prime}-\lim _{n \rightarrow 0} h / G^{\prime}(1)=\delta\left(\lim _{n \rightarrow 0} f^{\prime}\right)-k / G^{\prime}(1) .
$$

Given Lemma 1, the existence of a positive critical mass requires the necessary and sufficient condition that $\lim _{n \rightarrow 0} d p(n, n) / d n>0$. As the Theorem describes, there are three sets of conditions under which the condition of the Lemma is met and therefore a positive critical mass results. Firstly, when network goods have no intrinsic (non-network) value, i.e., $\mathrm{k}=0$, then the last term in equation (7) is zero. In markets with network externalities, $\lim _{n \rightarrow 0} \mathrm{f}^{\prime}>0$ and $\delta>$ 0 , therefore the whole expression of (7) is positive. This is the most straightforward case and applies directly to all two-way networks, such as telephone and fax networks. ${ }^{11}$

Secondly, a network has a positive critical mass if it exhibits very strong marginal network externalities when it is small, i.e., if $\lim _{n \rightarrow 0} h^{\prime}(n)=\lim _{n \rightarrow 0} \delta f^{\prime}(n)$ is sufficiently large. Then the first term in (7) dominates irrespectively of the values of other parameters. In particular it applies even when the goods have intrinsic value $(\mathrm{k}>0)$. For example, the value of a specialized computer program that relies mainly on support from other users can increase significantly when even few other users are added. Another good example is a newsgroup on internet with a very specialized subject.

Thirdly, a network has a positive critical mass if the density of high valuation types is sufficiently large (i.e., $\mathrm{G}^{\prime}(1)$ is large). Then, even if the marginal network externality is low, and

11 See Economides and White (1994) for a discussion of two-way networks. 
even if the network good has value in a network of size zero, the high density of consumers that flock to the network when it is almost of zero size allows for larger networks to be supported by higher prices, and therefore for a positive critical mass to arise. A good example of such a good is computer software with large sales but small externality for each unit sold.

Conversely, critical mass is zero if $\lim _{n \rightarrow 0} d p(n, n) / d n<0$. Inspection of (7) shows that this can be achieved only if $\mathrm{k}>0$, i.e., only if the good has some positive value even when the network is of zero size.

In a typical two-way network, $\mathrm{k}=0$. It follows that:

\section{Corollary 1: Two-way networks exhibit critical mass under perfect competition.}

\subsection{Welfare Maximization}

A planner who maximizes social welfare can fully internalize the network externality. The social welfare function is

$$
\mathrm{W}(\mathrm{n}, \mathrm{n})=\mathrm{B}(\mathrm{n}, \mathrm{n})-\mathrm{C}(\mathrm{n})=\mathfrak{b}_{\mathrm{f}}(\mathrm{p}(\mathrm{q}, \mathrm{n})-\mathrm{c}) \mathrm{dq}
$$

where the gross benefit of a network is $\mathrm{B}(\mathrm{n}, \mathrm{n})={ }_{b} \mathrm{p}(\mathrm{q}, \mathrm{n}) \mathrm{dq}$ and costs are $\mathrm{C}(\mathrm{n})={ }_{b} \mathrm{~b}$ cdq $=\mathrm{cn}$. If $\mathrm{W}(\mathrm{n}, \mathrm{n})$ is concave in $\mathrm{n},{ }^{12}$ the planner's optimum is defined by the first order condition

$$
\mathrm{dW} / \mathrm{dn}=\mathrm{dB}(\mathrm{n}, \mathrm{n}) / \mathrm{dn}-\mathrm{c}=\mathrm{p}(\mathrm{n}, \mathrm{n})+{ }_{b} \mathrm{p}_{2}(\mathrm{q}, \mathrm{n}) \mathrm{dq}-\mathrm{c}=0
$$

Further, since $p_{2}(q, n)=h^{\prime}(n) G^{-1}(1-q)>0$, it follows that $p_{2} d q>0$. Comparing (8) with (5), we see that, since $\mathrm{p}_{2} \mathrm{dq}>0$ and $\mathrm{W}(\mathrm{n}, \mathrm{n})$ is concave, the planner will choose a larger network size than the market equilibrium under perfect competition for any cost $\mathrm{c}$.

Three observations are in order. First, the marginal social benefit of network expansion is larger than the benefit that accrues to a particular firm under perfect competition. Thus, in

$12 \mathrm{~W}(\mathrm{n}, \mathrm{n})$ is concave in $\mathrm{n}$ if $\mathrm{p}_{1}+2 \mathrm{p}_{2}+\mathrm{f}_{b}\left(\mathrm{p}_{21}+\mathrm{p}_{22}\right) \mathrm{dq}<0$. 
Figure 2(a) curve $d B(n, n) / d n$ lies everywhere above $p(n, n)$. This is a direct consequence of the fact the planner can internalize the network externality while perfect competition cannot. Second, all networks that have a critical mass under perfect competition will also have a critical mass under welfare maximization. This is because

$$
\lim _{n \rightarrow 0} d B(n, n) / d n=\lim _{n \rightarrow 0} p(n, n)+\lim _{n \rightarrow 0} \delta f^{\prime}(n) G^{-1}(1-n)>\lim _{n \rightarrow 0} p(n, n) .
$$

and the last term is positive for every network that exhibits critical mass under perfect competition. Third, if a network has a critical mass under welfare maximization, its critical mass is larger than the critical mass under perfect competition. Let $\mathrm{n}^{\mathrm{w}}$ be the critical mass of the welfare maximization problem, defined by $d^{2} B(n, n) / d n^{2}=d\left[p(n, n)+{ }_{b}^{b} p_{2} d q\right] / d n=0$. Since the critical mass under perfect competition, $\mathrm{n}^{0}$, is defined by $\mathrm{dp}(\mathrm{n}, \mathrm{n}) / \mathrm{dn}=0$, concavity of $\mathrm{W}$ in $n$ implies that $n^{w}>n^{0}$. Further, the marginal value of the welfare-maximizing network at its critical mass is larger than the price of perfect competition at its critical mass. That is, the maximum of $d B(n, n) / d n$ exceeds the maximum of $d p(n, n) / d n$. See Figure 2(a).

Combining these three effects, we observe that the social planner starts a network at a higher marginal cost than would a system of perfect competition. Its starting size (the network's critical mass) will be larger, and the network size will remain larger for all smaller marginal costs than the network supported by perfectly competitive market.

Theorem 2: A welfare-maximizing planner starts a network at a higher marginal cost than a system of perfect competitors. Thus, for some range of marginal costs, a welfare maximizing planner supports a network of positive size, while under perfect competition the network does not exist. The starting size of the welfaremaximizing network (its critical mass) is larger than in perfect competition, and it remains larger for smaller marginal costs. 
It follows trivially that

\section{Corollary 2: Perfect Competition is inefficient. It provides networks of smaller than optimal sizes.}

It is possible for the welfare maximizing network to exhibit positive critical mass, even when there is no positive critical mass under perfect competition. Such a case is shown in Figure 2(b), and it is a direct consequence of the fact that the social marginal benefit exceeds the private marginal benefit.

\section{Corollary 3: The welfare-maximizing solution may exhibit a positive critical mass, even when there is no positive critical mass under perfect competition.}

\subsection{Monopoly}

We can conceive of two different problems for a monopolist. In the first, the monopolist does not influence expectations. In the second, which is more interesting, the monopolist influences expectations. The problem of the monopolist who influences expectations (and thereby the size of the demand) is to maximize profits

$$
\Pi^{\mathrm{M}}(\mathrm{n}, \mathrm{n})=\mathrm{R}^{\mathrm{M}}(\mathrm{n})-\mathrm{C}(\mathrm{n})=\mathrm{n}(\mathrm{p}(\mathrm{n}, \mathrm{n})-\mathrm{c})
$$

Its first order condition is ${ }^{13}$

$$
\mathrm{d} \Pi^{\mathrm{M}} / \mathrm{dn}=\mathrm{MR}^{\mathrm{M}}-\mathrm{MC}=\mathrm{p}(\mathrm{n}, \mathrm{n})+\mathrm{ndp} / \mathrm{dn}-\mathrm{c}=\mathrm{p}(\mathrm{n}, \mathrm{n})+\mathrm{n}\left(\mathrm{p}_{1}+\mathrm{p}_{2}\right)-\mathrm{c}=0
$$

$13 \Pi^{\mathrm{M}}(\mathrm{n}, \mathrm{n})$ is concave in $\mathrm{n}$ if $\mathrm{d}^{2} \Pi^{\mathrm{M}} / \mathrm{dn}^{2}=2 \mathrm{dp}(\mathrm{n}, \mathrm{n}) / \mathrm{dn}+\mathrm{nd}^{2} \mathrm{p}(\mathrm{n}, \mathrm{n}) / \mathrm{dn}^{2}=2\left(\mathrm{p}_{1}+\mathrm{p}_{2}\right)+$ $\mathrm{n}\left(\mathrm{p}_{11}+\mathrm{p}_{22}+2 \mathrm{p}_{12}\right)<0$. 
since $M^{M}=p(n, n)+n d p / d n=p(n, n)+n\left(p_{1}+p_{2}\right)$. Clearly, this differs from perfect competition (equation (5)) depending on the sign of the term $d p / d n=p_{1}+p_{2}$. The earlier section on perfect competition provides an extensive analysis of the shape of the function $\mathrm{p}(\mathrm{n}, \mathrm{n})$. When the network exhibits positive critical mass under perfect competition, $p(n, n)$ increases for small $\mathrm{n}$ up to $\mathrm{n}=\mathrm{n}^{0}$, and decreases thereafter. At a network of critical mass size, $\mathrm{n}=\mathrm{n}^{0}$, the marginal revenue of the monopolist is equal to the willingness to pay for the marginal consumer; i.e., it is equal to price. Therefore, at that point the first order conditions of the monopolist and the perfectly competitive firms coincide. It follows that, for marginal cost $c^{0}=p\left(n^{0}, n^{0}\right)$ the monopolist also chooses a network of size $n^{0}$.

For $c>c^{0}$, the solution of the first order condition of the monopolist will be smaller than $\mathrm{n}^{0}$. However, in this cost range, the willingness to pay at the network size that the monopolist is willing to provide is smaller than marginal cost, since from (10),

$$
\mathrm{p}(\mathrm{n}, \mathrm{n})-\mathrm{c}=-\operatorname{ndp}(\mathrm{n}, \mathrm{n}) / \mathrm{dn},
$$

and this is negative because $d p(n, n) / d n>0$ for $n<n^{0}$. Therefore the monopolist provides no services for $c>c^{0}$. Thus, when the network exhibits critical mass under perfect competition, the monopolist starts the network at the same marginal cost $\mathrm{c}^{0}$ and at the same critical mass $\mathrm{n}^{0}$ as in perfect competition. For smaller costs, $\mathrm{c}<\mathrm{c}^{0}$, the monopolist provides a smaller network than perfect competition. The monopolist's network size as a function of marginal cost is shown in a bold line in Figure 2(a). The range of $\mathrm{MR}^{\mathrm{M}}$ over which the monopolist stays closed is shown as a dotted line. Once the network size $\mathrm{n}$ is determined, price is given by the demand line $\mathrm{p}(\mathrm{n}, \mathrm{n})$. Prices are of course higher than the perfectly competitive price (equal to marginal cost). ${ }^{14}$

14 This is immediate from (11) since for $\mathrm{c}<\mathrm{c}^{0}$ we have $\mathrm{n}>\mathrm{n}^{0}$ and $\mathrm{dp}(\mathrm{n}, \mathrm{n}) / \mathrm{dn}<0$. 
If the network exhibits no critical mass under perfect competition and $d p(n, n) / d n<0$ for all $\mathrm{n}$, the monopolist will choose a lower network size and a higher price than perfect competition for all costs, as shown by the bold line in Figure 2(b). ${ }^{15}$

Theorem 3: A monopolist who can influence expectations will generally choose a smaller network size and charge a higher price than under perfect competition. The critical mass of the monopolist coincides with that of perfect competition. At that critical mass only, the monopolist prices at marginal cost; then at that point only, the behavior of the monopolist coincides with perfect competition.

\section{Corollary 4: Despite his influence on expectations, a monopolist who influences expectations supports a network which is smaller and more inefficient than perfect competition from a social welfare point of view.}

The interesting result here is that the monopolist never supports a network of larger size than perfect competition despite the fact that he can influence expectations and thereby internalize the network externality. The influence on expectations creates an incentive to expand the network, but this is more than counterbalanced by the usual incentive of a monopolist to restrict production. In equilibrium, the monopolist operates a network only where his marginal revenue falls below price; otherwise, equating marginal cost and marginal revenue would lead to losses. Marginal revenue falls below price for network sizes where the influence on expectations is superseded by the negative slope of the demand curve. And in this range, the size of the network of the monopolist is smaller than under perfect competition. Of course, a perfectly price discriminating monopolist would have been able to implement a pricing scheme that would

15 Of course, provided that the profit function of the monopolist is concave. 
internalize the externalities. An advantage that a monopolist may have over perfect competition is the higher likelihood of reaching the $n>0$ rather the $n=0$ equilibrium. The monopolist who influences expectations can create the necessary coordination to reach a positive network size, while coordination among competing firms may be difficult.

The problem of a monopolist who cannot influence expectations is even more straightforward. He maximizes

$$
\Pi\left(n, n^{e}\right)=n\left(p\left(n, n^{e}\right)-c\right)
$$

His first order condition evaluated at $n^{e}=n$ is

$$
\partial \Pi / \partial n=p(n, n)+n p_{1}-c=p(n, n)-n h(n) G^{\prime}\left(G^{-1}(1-n)\right)-c=0 .
$$

Comparing (13) with (10), it is clear that the monopolist who does not influence expectations will restrict the size of the network even further than the monopolist who influences expectations.

Theorem 4: A monopolist who does not influence expectations supports a smaller network than the monopolist who can influence expectations.

Corollary 5: From a social welfare point of view, the choice of a monopolist who does not influence expectations is more inefficient than that of a monopolist who influences expectations.

\subsection{Oligopoly Within a Network of Homogeneous Compatible Goods}

Oligopoly on network goods can take a variety of forms. First, oligopolists may produce the same good on the network and compete in quantities. Then each firm reaps the network externality of the whole network. Second, oligopolists may produce differentiated but compatible 
goods; again each reaps the network externality of the whole network. Third, some firm(s) may choose to produce goods that are incompatible with goods of other producers. Fourth, there may be incompatible differentiated goods. In the case of total or partial incompatibility, the set of firms is partitioned according to the compatibility standard adhered to by its members, and each reaps the network externality of the group to which it belongs. We will now consider only the case where firms produce compatible goods, and we will assume that firms choose quantities non-cooperatively. ${ }^{16}$ The models of perfect competition as well as the present model of compatible components are most appropriate for the application to the fax market in section 4.5.

Let the expectation of production of firm $\mathrm{i}, \mathrm{i}=1, \ldots, \mathrm{n}$, be $\mathrm{n}_{\mathrm{i}}^{\mathrm{e}}$, and actual production be $\mathrm{n}_{\mathrm{i}}$. The total expected size of the network is $\Sigma_{\mathrm{i}} \mathrm{n}_{\mathrm{i}}^{\mathrm{e}}$, and the network externality is $\mathrm{h}\left(\Sigma_{\mathrm{i}} \mathrm{n}_{\mathrm{i}}^{\mathrm{e}}\right)$. The willingness to pay for type $y$, given these expectations, is $y h\left(\Sigma_{i} n_{i}^{e}\right)$. Firms $i$ and $j$ are both in business if firms quote equal prices, because $y h\left(\Sigma_{\mathrm{i}} n_{\mathrm{i}}^{\mathrm{e}}\right)-\mathrm{p}_{\mathrm{i}}=\mathrm{yh}\left(\Sigma_{\mathrm{i}} \mathrm{n}_{\mathrm{i}}^{\mathrm{e}}\right)-\mathrm{p}_{\mathrm{j}} \Leftrightarrow \mathrm{p}_{\mathrm{i}}=\mathrm{p}_{\mathrm{j}}$. Calling $\mathrm{p}$ the common price, the marginal consumer $\mathrm{y}^{*}$ buying the good is defined by

$$
\mathrm{y}^{*}=\mathrm{m}\left(\mathrm{p}, \mathrm{h}\left(\Sigma_{\mathrm{i}} \mathrm{n}_{\mathrm{i}}^{\mathrm{e}}\right)\right)=\mathrm{p} / \mathrm{h}\left(\Sigma_{\mathrm{i}} \mathrm{n}_{\mathrm{i}}^{\mathrm{e}}\right),
$$

which is similar to equation (1). Since consumers of indices higher than $\mathrm{y}^{*}$ buy the good, the size of the network (demand) at price $\mathrm{p}$ is $\Sigma_{\mathrm{i}} \mathrm{n}_{\mathrm{i}}=1-\mathrm{G}\left(\mathrm{y}^{*}\right)$, or equivalently,

$$
\Sigma_{\mathrm{i}} \mathrm{n}_{\mathrm{i}}=1-\mathrm{G}\left(\mathrm{p} / \mathrm{h}\left(\Sigma_{\mathrm{i}} \mathrm{n}_{\mathrm{i}}^{\mathrm{e}}\right)\right) .
$$

Since $\mathrm{G}($.$) is strictly monotonic, we can write the willingness to pay of the last consumer in a$ network of size $\Sigma_{\mathrm{i}} \mathrm{n}_{\mathrm{i}}$ and expectations $\Sigma_{\mathrm{i}} \mathrm{n}_{\mathrm{i}}^{\mathrm{e}}$ as

$$
\mathrm{p}\left(\Sigma_{\mathrm{i}} \mathrm{n}_{\mathrm{i}}, \Sigma_{\mathrm{i}} \mathrm{n}_{\mathrm{i}}^{\mathrm{e}}\right)=\mathrm{h}\left(\sum_{\mathrm{i}} \mathrm{n}_{\mathrm{i}}^{\mathrm{e}}\right) \mathrm{G}^{-1}\left(1-\Sigma_{\mathrm{i}} \mathrm{n}_{\mathrm{i}}\right) .
$$

Firm $j$ chooses $n_{j}$ to maximize

${ }^{16}$ The analysis in a model of differentiated compatible goods would be similar. Competition among incompatible networks is qualitatively different; it is the subject of current work in Economides and Flyer (1995). 


$$
\Pi_{j}=n_{j}\left[p\left(\Sigma_{i} n_{i}, \Sigma_{i} n_{i}^{e}\right)-c\right]
$$

As in monopoly, there are two possible problems under oligopoly. In the first, oligopolists do not influence expectations. In the second, each oligopolist influences its expected output through its quantity choice. We turn to this problem first. The jth oligopolist sets $n_{j}^{e}=n_{j}$ before maximizing profits. Then, its objective is

$$
\Pi_{j}=n_{j}\left[p\left(\Sigma_{i} n_{i}, n_{j}+\sum_{i \neq j} n_{i}^{e}\right)-c\right] .
$$

Its first order condition is

$$
\begin{aligned}
\mathrm{d} \Pi_{\mathrm{j}} / \mathrm{n}_{\mathrm{j}} & =\mathrm{MR}_{\mathrm{j}}-\mathrm{MC}=\mathrm{p}\left(\sum_{\mathrm{i}} \mathrm{n}_{\mathrm{i}}, \mathrm{n}_{\mathrm{j}}+\sum_{\mathrm{i} \neq \mathrm{j}} \mathrm{n}_{\mathrm{i}}^{\mathrm{e}}\right)+\mathrm{n}_{\mathrm{j}} \mathrm{dp} / \mathrm{dn}_{\mathrm{j}}-\mathrm{c} \\
& =\mathrm{p}\left(\sum_{\mathrm{i}} \mathrm{n}_{\mathrm{i}}, \mathrm{n}_{\mathrm{j}}+\sum_{\mathrm{i} \neq \mathrm{j}} \mathrm{n}_{\mathrm{i}}^{\mathrm{e}}\right)+\mathrm{n}_{\mathrm{j}}\left(\mathrm{p}_{1}+\mathrm{p}_{2}\right)-\mathrm{c}=0 .
\end{aligned}
$$

At equilibrium expectations are fulfilled, so that $\mathrm{n}_{\mathrm{i}}^{\mathrm{e}}=\mathrm{n}_{\mathrm{i}}$, for all $\mathrm{i}$.

Clearly, for network size $n^{0}$ (where $p_{1}+p_{2}=0$ ), the first order condition of oligopoly coincides with that of perfectly competitive firms and of a monopolist who influences expectations. Therefore, at marginal cost $c^{0}=p\left(n^{0}, n^{0}\right)$, the size of a network of oligopolists is $\mathrm{n}^{0}$ and coincides with that of perfect competition and monopoly. For $\mathrm{c}>\mathrm{c}^{0}$, oligopolists would choose a network of size $\Sigma_{\mathrm{i}} \mathrm{n}_{\mathrm{i}}<\mathrm{n}^{0}$. However, for these costs, the oligopoly price would fall below marginal cost,

$$
\mathrm{p}\left(\sum_{\mathrm{i}} \mathrm{n}_{\mathrm{i}}, \Sigma_{\mathrm{i}} \mathrm{n}_{\mathrm{i}}\right)-\mathrm{c}=-\mathrm{n}_{\mathrm{j}}\left(\mathrm{p}_{1}+\mathrm{p}_{2}\right)<0
$$

because $\mathrm{p}_{1}+\mathrm{p}_{2}>0$ for $\Sigma_{\mathrm{i}} \mathrm{n}_{\mathrm{i}}<\mathrm{n}^{0}$. Therefore oligopolists will not produce for $\mathrm{c}>\mathrm{c}^{0}$.

For $\mathrm{c}<\mathrm{c}^{0}$, the marginal revenue for oligopolist $\mathrm{j}$ falls between the marginal revenue of a perfectly competitive firm and of the monopolist who influences expectations (if they were operating a network of the same size), 


$$
\mathrm{MR}^{\mathrm{M}}<\mathrm{MR}_{\mathrm{j}}<\mathrm{p} \Leftrightarrow \mathrm{p}+\left(\Sigma_{\mathrm{i}} \mathrm{n}_{\mathrm{i}}\right)\left(\mathrm{p}_{1}+\mathrm{p}_{2}\right)<\mathrm{p}+\mathrm{n}_{\mathrm{j}}\left(\mathrm{p}_{1}+\mathrm{p}_{2}\right)<\mathrm{p} .
$$

$\mathrm{MR}_{\mathrm{j}}$ is shown in Figure 2 between $\mathrm{MR}^{\mathrm{M}}$ and $\mathrm{p}(\mathrm{n}, \mathrm{n})$. Thus, oligopolists that influence expectations choose an equilibrium network size that lies between the perfectly competitive size and the network size of a monopolist who influences expectations.

Theorem 5: Cournot competition among oligopolists on the same network who are able to influence expectations of their own output results in an equilibrium network size that lies between the perfectly competitive size and the size chosen by a monopolist who influences expectations.

Corollary 6: From a social welfare point of view, the equilibrium of oligopolists that influence expectations is more inefficient than the perfectly competitive outcome but more efficient than the choice of a monopolist who influences expectations.

An oligopolist who cannot influence expectations has marginal profit (evaluated at $n_{\mathrm{i}}^{\mathrm{e}}=$ $\left.n_{\mathrm{i}}\right)$

$$
\mathrm{d} \Pi_{\mathrm{j}} / \mathrm{n}_{\mathrm{j}}=\mathrm{p}\left(\Sigma_{\mathrm{i}} \mathrm{n}_{\mathrm{i}}, \Sigma_{\mathrm{i}} \mathrm{n}_{\mathrm{i}}\right)+\mathrm{n}_{\mathrm{j}} \mathrm{p}_{1}-\mathrm{c} .
$$

This is smaller than the marginal profit of the oligopolist who influences expectations because it does not include the positive term $n_{j} p_{2}$. Thus, oligopolists who do not influence expectations support a smaller network than their counterparts who influence expectations. It is also easy to show that oligopolists who do not influence expectations support a larger network than a monopolist who does not influence expectations.

In summary, perfect competition, monopoly, and oligopoly of compatible goods exhibit the same critical mass size. Thus, in each of these markets the network starts with the same 
coverage and at the same marginal cost. The expansion of the network as marginal cost decreases follows slower rates for oligopoly and monopoly.

\section{Dynamic Industry Model under Perfect Competition}

In this section, we focus on dynamic models of markets for network goods under perfect competition that are suitable for examining the behavior of markets in which the marginal cost of production declines over time. The assumption of declining marginal costs is motivated by the observation that production costs for the new goods typically decline over time due to declining costs of inputs and technological progress (process innovation or learning by doing). The dynamic model assumes an exogenous time path for the marginal cost of production and solves for the equilibrium time paths of prices and quantities (network sizes). In section 4.1, the equilibrium time path for the network size is characterized by a discrete jump to the level of the critical mass of the network once the marginal cost of production falls to given level.

In section 4.2, we introduce a finitely elastic supply curve. This rules out infinitely large instantaneous supply. The model with finitely elastic supply also implies that rational consumers rule out the possibility of discontinuous growth paths in their expectations, thereby reducing the set of feasible equilibria. Thus, the set of equilibrium time paths is reduced to a single path which is uniquely determined by the initial size of the network (zero in this case).

We want to give quantitative content to the qualitative prediction that network externalities result in "rapid growth". If we were to observe a time path in which the network size were growing at an explosive rate, this would be consistent with the existence of network externalities, but observationally indistinguishable from plausible diffusion or growth models in which externalities play no role. Hence, a second virtue of the model below is that it encompasses a standard diffusion model as a special case, thereby providing a framework in which the model structure can used to identify the externality effect. The solution to the model depends on a parameter that indexes the strength of the externality effect, where a value of zero 
implies no consumption externality. If data are available on prices, quantities, and the distribution of types, then this parameter is identified in the econometric sense. Thus, the structural model gives positive content to the quantitative predictions of the model.

We discuss facsimile (fax) machines as an example of a network good that has shown dramatic expansion in the 80's. Although faxes predate the telegraph, their importance increased dramatically with the introduction of the G2 transmission standard in 1979-80. Still, sales did not pick up until the falling costs of semiconductors and integrated circuits decreased production costs of fax machines in the early 80's. We argue that production costs eventually reached a critical point at which significant network effects were enabled and price equilibria came into existence. Simple plots of the time series for prices and quantities reveal explosive growth during the mid-80's following a rapid decline in prices, thus seeming to confirm this prediction of the model. As our fax example indicates, there are many instances where it is not empirically accurate to treat the network good as non-durable. ${ }^{17}$ Since many other network goods like computer software have similarly long service lives, we include in section 4.3 an extension of the model to accommodate durable goods.

\subsection{Infinitely Elastic Supply}

It is straightforward to extend the static model under perfect competition to a dynamic framework. In contrast to the static case, we now assume that consumers form expectations over the present value and future time paths of the network size $\mathrm{n}^{\mathrm{e}}(\mathrm{t})$ and the price of the (nondurable) network good $\mathrm{p}^{\mathrm{e}}(\mathrm{t})$. We assume that these expectations are formed taking into account the expected future time path of industry marginal cost $c(t)$, and that these expectations are formed rationally and held in common.

17 Fax usage has both durable and non-durable components. The machine is durable, but phone services and fax paper are non-durable. In a full empirical implementation, it would be desirable and advantageous to model the joint decision since such a model could make use of aggregate data on fax paper consumption in addition to machine purchases. 
Let instantaneous utility of owning the network good for consumer type y and network of size $\mathrm{n}$ be given by $\mathrm{u}(\mathrm{y}, \mathrm{n})$. Since the good is non-durable, the consumer's consumption problem is static. Thus, the marginal consumer $\mathrm{y}^{*}(\mathrm{t})$ is characterized by a straightforward extension of equation (1), namely

$$
\mathrm{y}^{*}(\mathrm{t})=\mathrm{m}\left(\mathrm{p}^{\mathrm{e}}(\mathrm{t}), \mathrm{n}^{\mathrm{e}}(\mathrm{t})\right)=\mathrm{p}^{\mathrm{e}}(\mathrm{t}) / \mathrm{h}\left(\mathrm{n}^{\mathrm{e}}(\mathrm{t})\right)
$$

Summing over individual demands (i.e., the density of individuals with type less than $\mathrm{y}^{*}(\mathrm{t})$ ), total market demand for the network good at time $\mathrm{t}$ is given by

$$
\mathrm{n}(\mathrm{t})=1-\mathrm{G}\left(\mathrm{p}^{\mathrm{e}}(\mathrm{t}) / \mathrm{h}\left(\mathrm{n}^{\mathrm{e}}(\mathrm{t})\right)\right)
$$

Under the assumption of infinitely elastic and perfectly competitive supply, the inverse supply function is given by setting price equal to marginal costs: $p(t)=c(t)$. Thus, under the assumptions of market clearing and rational expectations, equilibrium prices are determined trivially by marginal costs, and the equilibrium network size is implicitly defined by the functional equation

$$
\mathrm{n}(\mathrm{t})=1-\mathrm{G}(\mathrm{c}(\mathrm{t}) / \mathrm{h}(\mathrm{n}(\mathrm{t})))
$$

The solution to this equation can be characterized using results in Cabral (1990). His "benefit flow" function B is defined here in terms of our primitives as

$$
B(y, n, t)=u(y, n(t))-p(t)
$$

It is easy to verify that our benefit function satisfies the conditions assumed in Cabral. In particular, our benefit function is continuously differentiable, satisfies $B_{y}>0, B_{n}>0$, and $B_{t}$ $>0$, and the distribution of types $\mathrm{G}(\mathrm{y})$ is smooth. Therefore, it follows from Cabral (1990) that there are multiple equilibria, and that equilibrium adoption paths $n(t)$ are discontinuous. The multiplicity of equilibria is analogous to the multiplicity found in the static model discussed 
earlier, and the discontinuity of $\mathrm{n}(\mathrm{t})$ confirms the conjecture formed using the intuition from the static model at the beginning of the previous section.

\subsection{Finitely Elastic Supply}

While the multiplicity of equilibria is not an uncommon result in models of this sort ${ }^{18}$ (and can be remedied in an ad hoc way by introducing a selection rule), the discontinuity of the time path is empirically counterfactual. This is because it implies an infinite instantaneous rate of supply at the discontinuity. In this section, we address both the multiplicity and discontinuity of equilibria by introducing a finitely elastic supply curve. ${ }^{19}$ Intuitively, this modification rules out discrete jumps in equilibrium since such jumps could only be supported by infinite prices. A second desirable implication of this assumption is that the set of multiple equilibria is reduced to a single time path.

We introduce an imperfectly elastic supply curve by assuming that the marginal cost of supply $\mathrm{c}\left(\mathrm{t}, \mathrm{n}^{\prime}(\mathrm{t})\right)$ is upward sloping in the instantaneous rate of supply, so that $\mathrm{c}_{\mathrm{n}^{\prime}}>0$. The equilibrium price path is then solved by setting $\mathrm{p}(\mathrm{t})=\mathrm{c}\left(\mathrm{t}, \mathrm{n}^{\prime}(\mathrm{t})\right)$, and the equilibrium time path for the network size is implicitly defined by the ordinary differential equation

$$
n(t)=1-G\left(c\left(t, n^{\prime}(t)\right) / h(n(t))\right)
$$

Though non-linear, the existence, uniqueness, and continuity properties of the solutions to the differential equation in (25) are standard results. A closed-form expression for the solution is not generally available, but we can compute solutions using standard techniques from numerical analysis. Some examples of numerical solutions are provided below in section 4.4.

18 See also Howitt and McAfee (1988).

19 The effects of this assumption can actually be made quite weak, since we can force the slope of this function to be infinitesimally small. 


\subsection{Durable Goods}

We now extend the model by considering durable goods. Let the instantaneous utility of owning the network good for a consumer of type $y$ and a network of size $n$ be given by $u(y$, n). Assume for simplicity that once a good is purchased, it yields an infinite stream of future utility. Thus, given an expected future time path of network size $n^{\mathrm{e}}(\mathrm{t})$, the present value of a machine purchase at time $\mathrm{t}$ for a consumer of type $\mathrm{y}$ is given by

$$
\mathrm{V}\left(\mathrm{y}, \mathrm{t}, \mathrm{n}^{\mathrm{e}}(\mathrm{t})\right)=\oint \mathrm{e}^{-\rho \mathrm{s}} \mathrm{u}\left(\mathrm{y}, \mathrm{n}^{\mathrm{e}}(\mathrm{s})\right) \mathrm{ds}
$$

where $\rho$ is the discount rate.

Suppose that the durable good is offered at time $t$ at price $\mathrm{p}(\mathrm{t})$. If it is purchased at time $t$, the present value of its cost is

$$
q(t)=e^{-\rho t} p(t)
$$

Consumers choose to purchase the good at time $t^{*}$ to maximize the objective function $V(y, t$, $\left.\mathrm{n}^{\mathrm{e}}(\mathrm{t})\right)-\mathrm{q}(\mathrm{t})$. Assuming that this function is concave (over the relevant range), $\mathrm{t}^{*}$ is characterized by $^{20}$

$$
\mathrm{V}^{\prime}\left(\mathrm{y}, \mathrm{t}^{*}, \mathrm{n}^{\mathrm{e}}\left(\mathrm{t}^{*}\right)\right)-\mathrm{q}^{\prime}\left(\mathrm{t}^{*}\right)=0
$$

This expression simplifies to ${ }^{21}$

$$
\mathrm{u}\left(\mathrm{y}, \mathrm{n}^{\mathrm{e}}\left(\mathrm{t}^{*}\right)\right)=\rho \mathrm{p}\left(\mathrm{t}^{*}\right)-\mathrm{p}^{\prime}\left(\mathrm{t}^{*}\right) \equiv \lambda\left(\mathrm{t}^{*}\right)
$$

This equation implicitly defines the optimal purchase date $t^{*}$ for a consumer of type $y$. Alternatively, we can use this equation to implicitly define the index value $y^{*}$ of the consumer who, given the expected price and network size paths, is just indifferent to purchasing a machine

20 We further assume that there exists a compact domain of $t$ such that $V\left(y, t, n^{e}(t)\right)>0$.

${ }^{21} \mathrm{~V}^{\prime}-\mathrm{q}^{\prime}=-\mathrm{e}^{-\rho \mathrm{t}} \mathrm{u}\left(\mathrm{y}, \mathrm{n}^{\mathrm{e}}(\mathrm{t})\right)+\rho \mathrm{e}^{-\rho \mathrm{t}} \mathrm{p}(\mathrm{t})-\mathrm{e}^{-\rho \mathrm{t}} \mathrm{p}^{\prime}(\mathrm{t})=0$, so that $\mathrm{u}\left(\mathrm{y}, \mathrm{n}^{\mathrm{e}}(\mathrm{t})\right)=\rho \mathrm{p}\left(\mathrm{t}^{*}\right)-\mathrm{p}^{\prime}\left(\mathrm{t}^{*}\right)$. 
at time t. We denote the function so defined by $m\left(p(t), n^{e}(t), t\right)$. That is, this function denotes the index value of the marginal consumer. Consumers for whom $y>m\left(p(t), n^{e}(t), t\right)$ have already purchased the durable good at time $\mathrm{t}$. Thus, the network size $\mathrm{n}$ at time $\mathrm{t}$ is given by integrating the unit demands of these consumers:

$$
n(t)=f_{n(p(t), n e(t), t)}^{6} d G(y)=1-G\left(m\left(p(t), n^{e}(t), t\right)\right)
$$

Suppose now that the instantaneous consumer utility function is multiplicative in types, i.e., $u(y, n)=y h(n)$. Then we can use equation (29) to solve for the function $m$ :

$$
\mathrm{m}\left(\mathrm{p}(\mathrm{t}), \mathrm{n}^{\mathrm{e}}(\mathrm{t}), \mathrm{t}\right)=\lambda(\mathrm{t}) / \mathrm{h}\left(\mathrm{n}^{\mathrm{e}}(\mathrm{t})\right)
$$

This in turn allows to write the demand equation (30) as

$$
\mathrm{n}(\mathrm{t})=1-\mathrm{G}\left(\lambda(\mathrm{t}) / \mathrm{h}\left(\mathrm{n}^{\mathrm{e}}(\mathrm{t})\right)\right)
$$

The shadow price $\lambda(\mathrm{t})$

$$
\lambda(t) \equiv \rho p(t)-p^{\prime}(t)
$$

plays exactly the same role in equation (32) as price $p(t)$ plays in equation (2). ${ }^{22}$ In the durable goods case, $\lambda(t)$ represents the opportunity cost of buying the good at $t$ rather than $t+d t$. The first term $\rho p(t)$ measures the cost of waiting one period, assuming that the price remains the same. The second term reduces the cost of buying today by any price increase in the time increment $\mathrm{dt}$. Thus, $\lambda(\mathrm{t})$ represents the opportunity cost of buying today rather than tomorrow. Using this re-interpretation, we can apply and extend results from the non-durable analysis to the durable good case.

${ }^{22} \lambda(t)=\rho p(t)-p^{\prime}(t)$ is monotonic if $\lambda^{\prime}(t)=\rho p^{\prime}(t)-p^{\prime \prime}(t)<0$. For this it is sufficient that $\mathrm{p}(\mathrm{t})$ is decreasing and convex. 
In the dynamic setting, a fulfilled expectations equilibrium is a pair of paths of prices and sales $\{p(t), n(t)\}$ such that expectations are fulfilled and supply equals demand at every period, i.e., it fulfills:

$$
\begin{array}{ll}
\text { demand: } & \mathrm{n}_{\mathrm{D}}(\mathrm{t})=1-\mathrm{G}\left(\mathrm{p}^{\mathrm{e}}(\mathrm{t}) / \mathrm{h}\left(\mathrm{n}^{\mathrm{e}}(\mathrm{t})\right),\right. \\
\text { supply: } & \mathrm{p}(\mathrm{t})=\mathrm{c}\left(\mathrm{t}, \mathrm{n}_{\mathrm{S}}{ }^{\prime}(\mathrm{t})\right), \\
\text { fulfilled expectations of sales: } & \mathrm{n}(\mathrm{t})=\mathrm{n}^{\mathrm{e}}(\mathrm{t}), \\
\text { fulfilled expectations of prices: } & \mathrm{p}(\mathrm{t})=\mathrm{p}^{\mathrm{e}}(\mathrm{t}), \\
\text { market clearing: } & \mathrm{n}_{\mathrm{D}}(\mathrm{t})=\mathrm{n}_{\mathrm{S}}(\mathrm{t})=\mathrm{n}(\mathrm{t}),
\end{array}
$$

where $c\left(t, n_{S}{ }^{\prime}(t)\right)$ is the marginal cost at time $t$ which may depend on the size of output $n_{S}{ }^{\prime}(t)$ at $t$. In the next section, we apply this dynamic analysis to the fax market in the U.S.

As in the model for non-durable goods, we modify the model of durable goods by postulating a finitely elastic supply. In contrast to the non-durable goods model, the equilibrium growth path with this modification is described by a second order rather than first order differential equation. Imposing the market clearing condition under perfect competition (price equal to marginal cost), we get $\mathrm{p}(\mathrm{t})=\mathrm{c}\left(\mathrm{t}, \mathrm{n}^{\prime}(\mathrm{t})\right)$. Hence, $\mathrm{p}^{\prime}=\mathrm{c}_{\mathrm{t}}+\mathrm{c}_{\mathrm{n}^{\prime}} \mathrm{n}^{\prime \prime}$. This implies

$$
\lambda(t)=\rho c\left(t, n^{\prime}(t)\right)-c_{t}\left(t, n^{\prime}(t)\right)+c_{n^{\prime}}\left(t, n^{\prime}(t)\right) n^{\prime \prime}(t)
$$

Substituting this expression for $\lambda(t)$ into equation (32) yields the desired result. The existence, uniqueness, and continuity properties of the solution to this differential equation are standard results. Given two transversality conditions, this solution is unique. In the fax calibration of section 4.5 we use conditions $\mathrm{n}(0)=0, \mathrm{n}^{\prime}(0)=0$. Although this is appropriate for most networks, these conditions need to be modified for networks, such as the Internet, that enter market competition after they have accumulated significant coverage and a high rate of growth.

\subsection{A Numerical Example}


Because the nonlinear differential equations derived in the previous section do not have closed-form solutions, we illustrate the model by reporting numerical solutions to a representative problem. In particular, we assume the following functional forms and parameter values for the above model with finitely elastic and perfectly competitive supply:

$$
\begin{array}{ll}
\mathrm{u}(\mathrm{y}, \mathrm{n})=\mathrm{yh}(\mathrm{n}) & \\
\mathrm{h}(\mathrm{n})=\mathrm{k}+\delta \mathrm{n}^{\alpha} & \alpha=0.5, \mathrm{k}=0.1, \delta=1.0 . \\
\mathrm{G}(\mathrm{y})=\mathrm{e}^{\mathrm{y}-\mu} /\left(1+\mathrm{e}^{\mathrm{y}-\mu}\right) & \mu=5.0 \\
\mathrm{c}\left(\mathrm{t}, \mathrm{n}^{\prime}\right)=\mathrm{e}^{-\mathrm{t}}+\mathrm{dn}^{\prime} & \mathrm{d}=1.0
\end{array}
$$

The above assumptions are fairly standard. The assumption that the network has positive utility when the network size is zero describes, for example, a good like a computer operating system, where the good provides utility even in the absence of a network. It could also describe a good like a fax machine that can also function as a telephone. The utility of the good obviously depends also on the size of the network, and we have chosen an exponential utility function. The distribution of types is symmetric and chosen for its analytic convenience. Setting $\mu=5.0$ implies that virtually all consumer types receive at least some benefit from the good. Finally, the industry marginal cost $c\left(t, n^{\prime}\right)$ is linear in output with a slope of one, but is shifting downward over time according to $\mathrm{e}^{-t}$.

With these functional form assumptions, the differential equation governing the growth of the network is

$$
n^{\prime}=(k+\delta \sqrt{ })(\mu+\log (1-n)-\log (n))-e^{-t}
$$

Note that if we let $\delta=0$, this equation provides a model for growth in which the size of the market grows over time solely because of the decrease in prices. ${ }^{23}$ If $\delta=1$, so that externality effects are present, then the growth rate of the market is clearly higher, and increasing in $\mathrm{n}$.

${ }^{23}$ There are no other diffusion effects included here. For example, the model does not allow demonstration effects. 
Figure 3 presents numerical simulations of the equilibrium growth paths with and without externality effects. When $\delta=0$, the growth path tends to inherit the smooth s-shaped form of the distribution of types. In contrast, the growth path with $\delta=1$ displays a much steeper slope and reaches the maximum network size much faster. Additional simulations not shown here also confirm that as the slope of the industry supply curve approaches zero, the slope of the growth path over the initial region approaches infinity.

These numerical simulations illustrate that the identification of network externality effects in data will rely heavily on the $a$ priori assumptions about functional forms. The most important assumption of these is the distribution of types. In practice, an index of types could be constructed from a vector of buyer characteristics by estimating a discrete

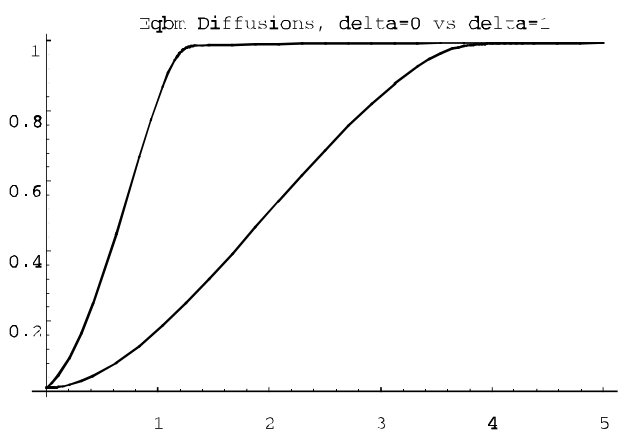
choice model. ${ }^{24}$ This model could then be combined with demographic data on the Figure 3: Diffusion of an innovation with and without network externalities. distribution of characteristics in order to compute the distribution of types over time. That is, such data would allow us to obtain an estimate of the function G(y). This knowledge of functional form would enable us to estimate the externality parameters $\delta$ and $\alpha$ using time series data on market prices and quantities.

\subsection{Demand Calibrations for the U.S. Market for Facsimile Machines}

24 See the discussion in Berry, Levinsohn and Pakes (1995). 
The market for facsimile machines in the U.S. exploded during the mid-to-late 80s, with growth rates of the number of units shipped exceeding $150 \%$ in $1987 .^{25}$ We argue that this tremendous surge in demand was not driven as much by outside shifts in consumer demand and price reductions as it was by the "feedback" effect induced by both past increases and anticipated future increases in the size of the installed base. The anecdotal evidence is consistent with this interpretation since the most dramatic fall in prices occurred well before 1987 (see Figure 4). What is true about the previous year (1986), however, is that this is the year in which the rate at which prices were falling began to taper off. This is an important clue because in the consumer's solution to the dynamic, durable goods problem, the desire to postpone a purchase is proportional to $\lambda_{t}=\rho p(t)-p^{\prime}(t)$. This implies that as long as prices are still falling (that is, as long as $\left.p^{\prime}(t)<0\right)$, aggregate demand is weak. This is exactly what the data in Figure 4 seem to show.

We now formalize the above intuition with a simple calibration exercise. In addition to our data on the average prices and quantities of facsimile machines sold in the U.S. between 1979 and 1992, empirical estimation of our model requires data on the distribution of consumer characteristics. Ideally, these characteristics would be identified by collecting marketing data on consumers that purchase fax machines and then using these data to estimate a discrete choice model. In practice, however, access to such data is difficult, so we pursue an alternative strategy that is feasible with aggregate data. Even though most fax purchases are made by firms and not consumers, we argue that it is nonetheless reasonable and convenient to model the unit demand for fax machines as a function of consumer characteristics. This is because a firm's demand for fax machines ultimately is derived from "employee demand." For example, a firm with a high fraction of highly skilled white collar workers will have a higher demand for fax machines than a firm with a high fraction of production line workers. For simplicity and feasibility, we assume

\footnotetext{
25 The data we use was obtained from various issues of the Predicast Basebook.
} 


\section{Growth Rate of Installed Base vs. Price}

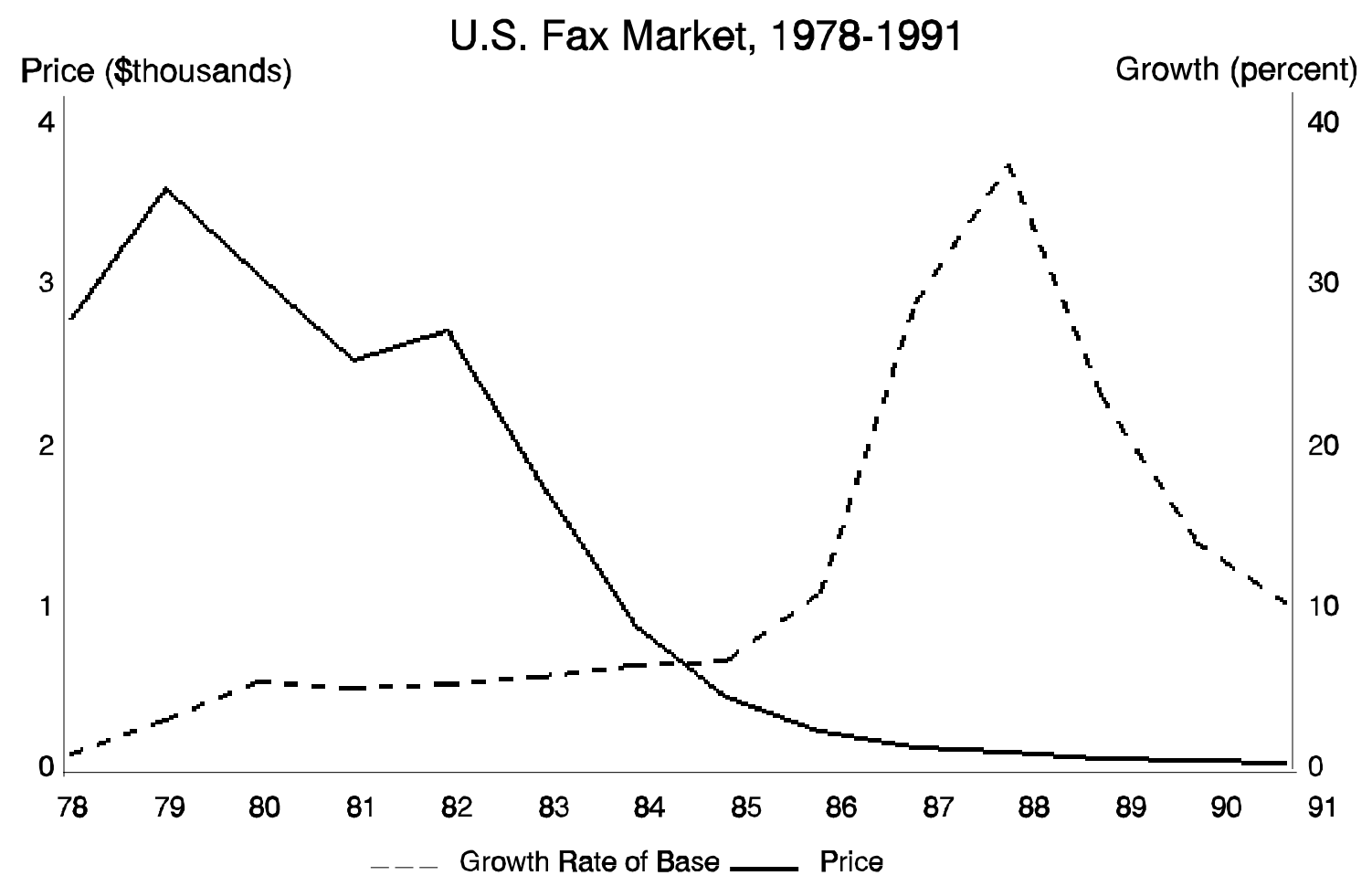

\section{Figure 4}

that the employee characteristics related to fax demand can be summarized by employees' income.

In order to characterize the distribution of consumer types as a function of consumer income, we use data on the distribution of income from the Current Population Survey (CPS) for survey years 1976, 1981, 1986, and 1991. Since income is approximately lognormal, we transform the data using natural log to obtain normally distributed log-income. We then calculate the mean and variance for each of the above four years and then interpolate to estimate the distribution of log-income for each year between 1979 and 1992. ${ }^{26}$ This gives us a time-varying

${ }^{26}$ To be specific, this procedure also requires that we account for top coding in the CPS. For each of the four years, we truncate above at $\$ 100,000$, except for 1976 , which is truncated 
estimate of the distribution function described in section 3, that is, $\mathrm{G}(\mathrm{y} ; \mathrm{t})$. We use the notation $\mu_{\mathrm{t}}$ and $\sigma_{\mathrm{t}}$ to denote the mean and standard deviation of log income, and the notation $\Phi(\mathrm{x})$ to denote the standard normal distribution. This notation allows us to represent our empirical estimate of $\mathrm{G}$ by

$$
\mathrm{G}(\mathrm{y} ; \mathrm{t})=\Phi\left(\left(\ln (\mathrm{y})-\mu_{\mathrm{t}}\right) / \sigma_{\mathrm{t}}\right)
$$

Next we normalize the size of the fax network by assuming that maximum potential network size is 20 million fax machines. This number implies a maximum ratio of about one fax machine for every five workers in the U.S. (we estimate the number of fax machines in 1992 to be about 7.6 million). In the results reported below, we experimented with both larger and smaller values of the maximum network size and this did not affect the calibration results reported below. To construct the "stock" of fax machines, that is, the installed base, we assume that fax machines depreciate at a rate of $13.3 \%$ per year, and used a perpetual inventory method to accumulate unit sales. ${ }^{27}$ Finally, we deflated our price series for fax machines using the GDP deflator reported in Table 1.1 of the Current Survey of Business.

With the above estimate of the distribution of consumer income $G(y ; t)$, our data on normalized network size, $n_{t}$, and real prices, $p_{t}$, we calibrate the model by choosing values of the

above at $\$ 80,000$. We also truncate below at $\$ 2000$ in order to avoid data problems with outliers. We then use formulas for the truncated mean and variance of a normal distribution to calculate means of log income (nominal) of 9.33, 9.38, 9.70, and 9.73 for the four years, respectively. The standard deviations of income in these four years are 1.18, 1.27, 1.31, and 1.33 , respectively. The interpolation is done using a cubic polynomial. Finally we converted these numbers to real 1987 dollars using the GDP deflator reported in Table 1.1 of the Survey of Current Business. We are extremely grateful to our colleague Rick Flyer for providing us with the estimates from the CPS.

27 We experimented with various depreciation rates and this did not significantly affect the calibration results reported below. We chose the depreciation rate of $13.3 \%$ by applying the average service life of telephones ( 7.5 years), which is estimated using life expectancy tables for consumer possessions used by insurance adjusters in responding to claims for fire and theft damage. We are grateful to Peter Klenow for providing us with this estimate. 
remaining unknown parameters to fit the model. We simplify the model somewhat by assuming that fax machines are pure network goods, so that they give no utility in a network of size zero. That is, we assume $\mathrm{k}=0$. This is not strictly true, since fax machines can also double as telephones, but given the widespread availability of telephones in most places where fax machines are used, it seems reasonable to assume that the fax machines are valued only for their ability to make fax transmissions.

We relax the simplifying assumption made in the previous section that $\gamma=1$. Thus, our general Cobb-Douglas utility specification is

$$
u\left(y_{t}, n_{t}^{e}\right)=A y_{t}^{\gamma} n_{t-1}^{\alpha}
$$

Note that we have made the assumption $\mathrm{n}_{\mathrm{t}}^{\mathrm{e}}=\mathrm{n}_{\mathrm{t}-1}$, that is, our empirical specification assumes that the expected size of the network this year is a linear function of the network size at the beginning of the year. ${ }^{28}$

Recalling our use of the notation $\lambda_{t}=\rho p_{t}-p_{t}^{\prime}$, we construct a data series for $\lambda_{t}$ by assuming $\rho=0.2$. Our results in the previous section show that the value of the marginal consumer is calculated by setting utility equal to $\lambda_{\mathrm{t}}$ and solving for $\mathrm{y}_{\mathrm{t}}$. Taking natural $\operatorname{logs}$ of the resulting expression yields

$$
\ln y_{t}=\gamma^{-1}\left(\ln \lambda_{t}-\alpha \ln n_{t-1}-\ln A\right)
$$

Using our empirical estimate of the distribution of consumer income, the equilibrium network size is given by

$$
\mathrm{n}_{\mathrm{t}}=1-\Phi\left(\left(\ln \mathrm{y}_{\mathrm{t}}-\mu_{\mathrm{t}}\right) / \sigma_{\mathrm{t}}\right) \text {. }
$$

Inverting $\Phi$ and solving this expression for $\ln \left(\mathrm{y}_{\mathrm{t}}\right)$ yields

28 Imposing a coefficient of one is arbitrary and reflects the fact that the constant term A absorbs this scaling factor in any case. 


$$
\sigma_{t} \Phi^{-1}\left(1-n_{t}\right)+\mu_{t}=\ln y_{t} .
$$

Since the inverse of the cumulative standard normal is easily calculated, and since $\sigma_{t}, n_{t}$, and $\mu_{t}$ are observable, we can construct the term on right side of the above expression. We define this variable using the notation $g_{t}=\sigma_{t} \Phi^{-1}\left(1-n_{t}\right)+\mu_{t}$. Finally, substituting our expression for the marginal consumer yields our estimating equation

$$
g_{t}=\beta_{0}+\beta_{1} \ln \lambda_{t}+\beta_{2} \ln n_{t-1}+e_{t}
$$

where $\beta_{0}=-\gamma^{-1} \ln A, \beta_{1}=\gamma^{-1}, \beta_{2}=-\gamma^{-1} \alpha$, and $e_{t}$ is an error term that represents approximation errors in the functional form assumptions as well as errors in the measurement of $\mathrm{g}_{\mathrm{t}}$.

We estimate this equation using OLS. We point out that equation (41) is essentially a demand equation in which a nonlinear transformation of the quantity variable appears on the left side of the equation and a price term $\left(\lambda_{t}\right)$ and a demand shifter $\left(n_{t-1}\right)$ appear on the right side of the equation. ${ }^{29}$ Table 1 reports the estimates of the model for three variations of the above specification. For Model 1, the estimates reveal a positive coefficient on the price term, as predicted, and a negative coefficient on the network term, also as predicted. Both coefficients (as well as the coefficient estimates reported for models 2 and 3) are estimated with tight standard errors, although we hasten to emphasize that these standard error estimates can be misleading given the small size of our sample. We include them merely to provide some indication of the model's fit. We note that goodness of the calibration fit is also revealed by the high $\mathrm{R}^{2}$ value of 0.902 .

\section{Table 1: Calibration Estimates}

${ }^{29}$ Our OLS estimates are potentially biased for the usual reason that the error term $e_{t}$ could contain shocks to supply, in which case the price term would be endogenous. Given our data limitations, we ignore this issue. 


\begin{tabular}{|l|ccc|}
\hline Variable & Model 1 & Model 2 & Model 3 \\
\hline Constant & -0.501 & -0.632 & -1.401 \\
& $(0.050)$ & $(0.051)$ & $(1.386)$ \\
$\ln \lambda_{\mathrm{t}}$ & 0.118 & $\ldots$ & $\ldots$ \\
& $(0.023)$ & & \\
$\ln \lambda_{\mathrm{t}-1}$ & $\ldots$ & 0.142 & 0.129 \\
& & $(0.020)$ & $(0.032)$ \\
$\ln \mathrm{n}_{\mathrm{t}-1}$ & -0.582 & -0.574 & -0.616 \\
& $(0.034)$ & $(0.026)$ & $(0.081)$ \\
Time & $\ldots$ & $\ldots$ & 0.008 \\
& & & $(0.015)$ \\
\# Obs & 15 & 14 & 14 \\
Adj. $\mathrm{R}^{2}$ & 0.902 & 0.951 & 0.947 \\
\hline
\end{tabular}

Note: Standard errors appear in parentheses.

The coefficient estimates for models 2 and 3 largely confirm the results for model 1, and reveal them to be fairly robust to alternative assumptions. In model 2, we lag the price term $\ln \left(\lambda_{t}\right)$ to control for endogeneity. As expected, this slightly increases the coefficient on the price term, but the magnitude of the increase is not dramatic. Model 3 augments model 2 by adding a trend term. A significant trend would have indicated the possibility of a specification error, but the estimate here is insignificant.

Our structural specification of the empirical model allows us to interpret the coefficients on the price and network variables in terms of the preference and technology parameters of the model. Recall that the utility of the network for a consumer indexed by income level $y_{t}$ is given by $\mathrm{u}\left(\mathrm{y}_{\mathrm{t}}, \mathrm{n}_{\mathrm{t}}^{\mathrm{e}}\right)=\mathrm{Ay}_{\mathrm{t}} \mathrm{n}_{\mathrm{t}-1}{ }^{\alpha}$. Table 2 reports the estimates and standard errors of $\alpha$ and $\gamma$ implied by the reduced-form estimates in Table 1. The estimates of $\alpha$ range from 4.056 to 4.923, with standard errors of 1.171 and 2.023 respectively. These estimates provide a structural 
estimate of the utility attributable to the size of the installed base; the estimated market demand for fax machines is increasing in the size of the installed base. ${ }^{30}$

Table 2: Structural Parameters

\begin{tabular}{|c|ccc|}
\hline Parameter & Model 1 & Model 2 & Model 3 \\
\hline$\alpha$ & 4.923 & 4.056 & 4.775 \\
& $(2.023)$ & $(1.171)$ & $(2.200)$ \\
$\gamma$ & 8.465 & 7.063 & 7.755 \\
& $(2.801)$ & $(1.597)$ & $(2.518)$ \\
\hline
\end{tabular}

Note: Standard errors appear in parentheses.

\section{Concluding Remarks}

In this paper, we discussed the equilibrium size of networks under alternative market structures for both non-durable and for durable goods. In the presence of network externalities, we showed that, in a static model, for high marginal costs the size of network is zero; as costs fall, the network size abruptly increases to a positive and significant size (the critical mass) and thereafter it increases gradually as costs continue to fall. A welfare-maximizing planner supports a larger network than in perfect competition. Despite its influence on consumers' expectations, a monopolist always chooses a network of smaller size than in perfect competition. Oligopolists

30 These estimates imply that consumer utility is convex in the size of the installed base. While this does not violate the assumptions of our model, most of the theoretical literature assumes that utility is concave in the size of the network. One possible explanation for this result is that our estimate of $1 / \gamma$ (the coefficient on the price term $\ln \left(\lambda_{t}\right)$ ) is biased downward by measurement error, in which case our estimate of $\alpha$ is biased upward. When we simultaneously include both current and lagged values of the price term (not reported in the table), the sum of the price coefficients rises to 0.21 , the coefficient on the network effect drops to 0.50 , and the implied exponent of the installed base falls to $\alpha=2.5$. This sensitivity to price specifications suggests that future generalizations of the model and better measurement of the price term will lead to better estimates of the utility parameters. 
of compatible goods support networks of smaller size than perfect competition but larger than monopoly.

We generalized these results to a dynamic multi-period setting and to durable goods under perfect competition. In this framework, given a slightly inelastic supply curve, the abrupt increase of the network from zero to critical mass of the single-period model is replaced by a continuous but steep increase in network size. We applied our model to US fax market. Calibration of the model to the data suggests that its growth was strongly influenced by network externalities. 


\section{$\underline{\text { References }}$}

Antonelli, Cristiano, (1992), "The Economic Theory of Information Networks," in The Economics of Information Networks, Cristiano Antonelli (ed.), North Holland: Amsterdam.

Arthur, W. Brian, (1988), "Self-reinforcing Mechanisms in Economics," in P. Anderson and K. Arrow (eds.) The Economy as an Evolving Complex System, Addison Wesley.

Arthur, W. Brian, (1990), "Positive Feedbacks in the Economy," Scientific American, February 1990, pp. 92-99.

Berry, Steven, James Levinsohn, and Ariel Pakes, (1995), "Automobile Prices in Market Equilibrium," forthcoming, Econometrica.

Cabral, Luis, (1990), "On the Adoption of Innovations with 'Network' Externalities," Mathematical Social Sciences, vol. 19, pp. 229-308.

Cabral, Luis, and Antonio Leita, (1989), "Network Consumption Externalities: The Case of Portuguese Telex Service," in The Economics of Information Networks, Cristiano Antonelli (ed.), North Holland, 1992, pp. 129-40.

Economides, Nicholas, (1996a), "The Economics of Networks," forthcoming International Journal of Industrial Organization.

Economides, Nicholas, (1996b), "Network Externalities, Complementarities, and Invitations to Enter," forthcoming European Journal of Political Economy.

Economides, Nicholas and Rick Flyer, (1995), "Technical Standards Coalitions for Network Goods," mimeo.

Economides, Nicholas and Lawrence J. White, (1994), "Networks and Compatibility: Implications for Antitrust," European Economic Review, vol. 38, pp. 651-662.

Farrell, Joseph and Saloner, Garth (1985), "Standardization, Compatibility, and Innovation," Rand Journal of Economics, vol. 16, pp. 70-83.

Hayashi, Koichiro, (1992), "From Network Externalities to Interconnection," in The Economics of Information Networks, Cristiano Antonelli (ed.), North Holland: Amsterdam.

Howitt, Peter and Preston McAfee, (1988), "Stability of Equilibria with Externalities," Quarterly Journal of Economics, vol. 103, pp. 261-77.

Katz, Michael and Carl Shapiro, (1985), "Network Externalities, Competition and Compatibility," American Economic Review, vol. 75 (3), pp. 424-440.

Noam, Eli, (1992), "A Theory for the Instability of Public Telecommunications Systems," in The Economics of Information Networks, Cristiano Antonelli (ed.), North Holland: Amsterdam.

Rohlfs, Jeffrey, (1974), "A Theory of Interdependent Demand for a Communications Service," Bell Journal of Economics, vol. 5, pp. 16-37. 
Wilson, Robert, (1993), Nonlinear Pricing, Oxford University Press. 